\title{
Understanding School Leaders' Characteristics and Estimating the Future
}

\author{
Ali Sabanci ${ }^{1}$, Ahmet Şahin ${ }^{2}$, Gamze Kasalak ${ }^{1}$ \\ ${ }^{1}$ Faculty of Education, Akdeniz University, Antalya, Turkey \\ ${ }^{2}$ Cengiz Topel Secondary School, Antalya, Turkey \\ Email: ali_sabanci@yahoo.co.uk
}

Received April 17 $7^{\text {th }}, 2013$; revised May 22 $2^{\text {nd }}, 2013$; accepted June $8^{\text {th }}, 2013$

Copyright (C) 2013 Ali Sabanci et al. This is an open access article distributed under the Creative Commons Attribution License, which permits unrestricted use, distribution, and reproduction in any medium, provided the original work is properly cited.

\begin{abstract}
Responsiveness to the rapidly changing environment and a set of circumstances might be a key argument for educational leaders. We addressed the following specific questions: 1) What are your school leader's weak characteristics as a school leader? 2) What are your school leader's strong characteristics as school leaders? And 3) according to you, what kind of characteristics your school leader will need in the forthcoming twenty-five years as a school leader? The purpose of the study is to determine the strong and weak characteristics of current school leaders and trying to estimate and draw an overview about characteristics of future school leaders depending on the views of teachers. The study was conducted by qualitative interviewing. The study group in the research was determined by two types of purposeful sampling: 1) convenience sampling and 2) maximum variation sampling. The study group consisted of 56 teachers from various European countries. In the analysis, NVivo 10 was used and the data were analyzed by content analysis technique. The results illustrated that weak, strong and estimated characteristics as they were stated by the respondents were consistent in that they provided three kinds of data including weak and strong the characteristics of current school leaders, estimated future characteristics and a picture of the criteria to evaluate leadership Educating people undoubtedly will be based on "human relations", "face to face" and "in the classrooms teaching" while technology and its all kinds of derivatives are presumed only to be the means to reach the goals.
\end{abstract}

Keywords: Leadership; School Leader; Characteristics of Leaders; Leadership in Future

\section{Introduction}

In this study, we discussed current state of school leadership theoretically and tried to find answers to the characteristics of a school leader today and the characteristics which will be required in the near future regarding uncertainty of the future. Coates (2010) argues that the past is open to interpretation, the present to perception and the future is inevitably about speculation. Fink (2005) argues that leadership in recent years has become a growth industry. Politicians demand more of it, academics decry the lack of it, and potential school leaders are deciding "to hell with it".

In the OECD publications, it has been stressed that there is a growing concern that the role of school principal, has not evolved to deal with the complex challenges that schools are preparing children and young people to face in the 21 st century. So the major attention must be first on the need to improve teaching and learning, secondly, the change in pedagogy, thirdly, the shift in the centres of autonomy and accountability, fourthly, policy and practice coherency, and finally, schools are confronted with an increasingly complex environment. In this process the key elements for an effective school leadership needed were suggested to 1) be a more active role in instructional leadership, 2) providing a more powerful form of active, constructivist learning, 3 ) be sufficient autonomy to make im- portant decisions about the curriculum and teacher recruitment and development, 4) getting coherent governmental policy and practice with school-level processes, systems and priorities and 5) enabling teachers and students to deal effectively with the processes of change (OECD, 2009).

In the first section of this paper we raised some important questions on the current state of school leadership based on literature in order to create an impression of the flow of the logic of the paper. Later we tried to discuss how school leadership has been seen today and what kind of estimations about the characteristics of future school leaders have been suggested in the related literature. In the second section, the methodology has been explained. In the third part, the findings about first, the current state of leadership by means of strong and weak characteristics and secondly, findings about estimations for future leadership were given. In the final we discussed the findings and concluded.

\section{Literature Review}

The argument, on whether the principals are in the least favourable position to provide proactive leadership or not, lies behind the fact that "principals find themselves locked in with less and less room to manoeuvre (Fullan, 1998). The answer may be "yes" for many countries depending on the amount of 
principal's autonomy on the school policy. For example Leithwood et al. (2002) reported that the majority of the teachers and managers believe that the government's policies about improvement of teaching and learning do not reflect their own professional goals. If so, as Steinbach and Jantzi (2002) suggested further questions need to be addressed to seek for the reasons behind the fact and draw outcomes for the future of school leadership such as: Are the principals surrounded by a tight costume made of regulations? Is their unfavourable position because they are arrested by their psychological guards? Or is that because they are led by a conservative social pressure? And finally, how flexible are they to react to change demand? On the other hand, how rapid turnover or in other words instability in school management positions effects leadership characteristics and creates significant barriers to educational change (Fink \& Brayman, 2006). Each question is vital in that the possible convincing answers to each of them will help us to understand the characteristics of leadership today and provide inspiring clues to estimate how leaders will be in the future.

Grogan and Andrews (2002) noted that the changes in education, and the nation as a whole, could present an entirely different set of challenges about leadership in the future. As in Coates (2010) similitude "The established route of the train journey gives way to the flexibility of the car" Fullan (1998) claims that school leaders need a new mindset and guidelines for action to break through the bonds of dependency that have entrapped those who want to make a difference in their schools. Responsiveness to the rapidly changing environment and set of circumstances might be a key argument for educational leaders. Twenty-first century schooling necessitates a shift away from vertical, policy-driven change to lateral, capacity building change. Schools are becoming more complex places. In the future they will need to be more responsive to a rapidly changing environment and set of circumstances. They will need to be highly adaptable structures that are versatile and responsive to shifting needs and priorities. Therefore the leadership practice has to also be adaptive, flexible and highly responsive to external and internal imperatives for change (Harris, 2010; Leithwood et al., 2008). Barendsen and Gardner (2006) proposed that the best leaders to adjust to rapidly changing times need to exhibit three distinct meanings of good: 1) an excellent technical and professional quality and competence, 2) an ethical orientation, and 3) a completely engaged sense of fulfilment and meaningfulness. According to Coates (2010) a future thinking engages individuals and teams with innovation and there is a move from replication to regeneration, from predictability to possibility. Sandmann and Vandenberg (1995) asserted that leadership development for the 21st century is holistic: it is centred in groups or organizations, rather than individuals, and engages the group in heart, mind, spirit, and energy. The driving forces of this philosophy, then, are community, the heart of a group's leadership; vision, which engages the spirit; learning, which stimulates the mind; and action, which compels energy. Mariasse (1985) considered leaders as not to simply maintain the existing situation. To the writer, leaders are involved in change, and without change or movement, there is no leadership. To actively change an organization, leaders must make decisions about the nature of the desired state. Making choices requires both information about current realities and future possibilities. According to Reilly (2007) a global leader is a learner and believes that everyone around him is also a learner and values innovation. Collay (2006) writes that aspiring prin- cipals are urged to create democratic organizations and professional learning communities. These demanding educational settings require bold, socially responsible leadership by both principals and teachers, continually expanding the roles and responsibilities each must fulfil. Goldring (2002) concentrates on student achievement in explaining effective educational leadership in the 21 st century. He asserts that a leader will require strategies that make it possible for all children to succeed academically. Day et al. (2001) put a stress on the capacity of leaders to make a difference. They assert that interpretation of and responses to the constraints, demands and choices that they face help leaders to make a difference. Leaders capture their past, present and future pressures, challenges, and concerns and aspirations with which they are daily faced and which are reflect the multi-faceted demands of the role. Slater (2008) thinks that building leadership capacity or eliciting effort in others requires effort, unique insight, and explicit skills on the part of leaders. Leaders may learn to use communication skills and strategies as a pathway to building leadership capacity. As principals and other leaders share the lead and the load, the success of their performance will be determined by their ability to inspire a culture of empowerment. Leaders' success then will be measured not by the number of followers they have, but rather by the number of individuals that they have inspired to become leaders themselves. According to Witziers et al. (2003) principals should not only perform tasks related to coordination and evaluation of the educational system but also in relation to further developing the educational system via transformation of the school culture. One of the main tasks of school principals is to help create a working environment in which teachers collaborate and identify with the school's mission and goals. Murphy and Walberg (2002) points out to trust and dialogue. To them, new leaders dedicated to school improvement should gain knowledge not only about best practices but also about how to foster dialogue and trust within schools and between schools and the communities they serve. Moreover, school staff should be given the knowledge about new leadership concepts and scientific evidence that they need to accept innovative leaders. Grogan and Andrews (2002) point out to critical characteristics of a preparation of aspiring educational leaders programme such as collaborative instructional leadership, practice based knowledge, opportunities for novices and experts, selection of aspiring principals, assessment of development, contribution to standards, ethical and moral obligations, long term internship and learning opportunities in diverse settings and address to successors.

\section{Problem Statement}

The purpose of this article is to determine the strong and weak characteristics of current school leaders and trying to estimate and draw an overview about characteristics of future school leaders depending on the views of teachers. For this reason the following specific questions were addressed to them:

1) What are your school leader's weak characteristics?

2) What are your school leader's strong characteristics?

3) What kind of characteristics your school leader will need in the forthcoming twenty-five years as a school leader?

\section{Methodology}

Our research was based on phenomenological approach which is a qualitative research design. The data were gathered by qualitative interviewing using standardized open-ended interviews (Kus, 2007; Mason J., 2002; Patton, 1990; Rubin \& 
Rubin, 1995; Yildirim \& Simsek, 2006).

The interview form consisted of two parts. In the first part questions about demographic information took part with an explanation about the purpose of the study. In the second part, the respondents were addressed three specific questions to in order first to understand the current state (strong and weak characteristics of current education leaders) and secondly to explore some clues for future leadership characteristics.

The study group in the research was determined by two types of purposeful sampling: 1) convenience sampling was used for the countries other than Turkey because of the difficulty in interviewing the respondents and 2) maximum variation sampling was used for Turkish respondents considering gender, marital status, instruction type of schooling, school type, teaching subject and seniority (length in teaching position) (Patton, 1990; Yildirim \& Simsek, 2006). As a result the study group consisted of 56 teachers including 44 teachers from Antalya, Turkey, 1 from Austria, 1 from Germany, 2 from Norway, 1 from Portugal, 1 from Romania, 3 from South Cyprus, 2 from Spain and 1 from United Kingdom. 41.1\% (23) of the participants are male and 58.9\% (33) are female. 60.7\% (34) of the teachers are married; $39.3 \%(22)$ of the sample group are single. $75.0 \%$ (42) of the teachers work in full day education schools, the others, $25.0 \%$ (14) work in schools with half day education. $30(53.6 \%)$ of the teachers participated the study work in primary schools, $12(21.4 \%)$ in high schools, $4(7.1 \%)$ in secondary schools, $4(7.1 \%)$ in vocational high schools, $2(3.6 \%)$ in upper secondary schools, 2 (3.6\%) in Anatolian high schools, 1 $(18 \%)$ in pre-education schools and $1(1.8 \%)$ in informal edu- cation. The sample comprised of 23 kinds of teaching subjects. The participants had 1 year to 32 years of experience.

The data were gathered in 2012 spring semester. Turkish participants were interviewed face to face but e-mailing was preferred for the other participants. The data were analysed by content analysis technique in two ways. First, the interviews were read through in order to get a feel for what is being said, identifying key themes and issues in each text, then coded and categorized in themes. Secondly, in the analysis, NVivo 10, computer software package was used for further analysis. The respondents were coded as "T" and given a number" (Ex.T1) (Patton, 1990; Yildirim \& Simsek, 2006). In order to improve the validity and reliability transparency, consistency-coherency, and communicability were considered (Rubin \& Rubin, 1995).

\section{Results}

In this section, first coding similarity was discussed, and then results of teachers' views on current state of school leaders' characteristics and their estimations about future characteristics were presented in the sub-headings presented in medium italics.

According to Figure 1, the way the respondents understood and answered the questions were in the scope of research questions and quite similar.

Referring to teachers' views about principals' weak leadership characteristics twenty-two themes given in Table 1 were identified. Some quotations representing the themes have been presented in the following lines. In relation to the first theme one of the respondents said "Our school principal states that he

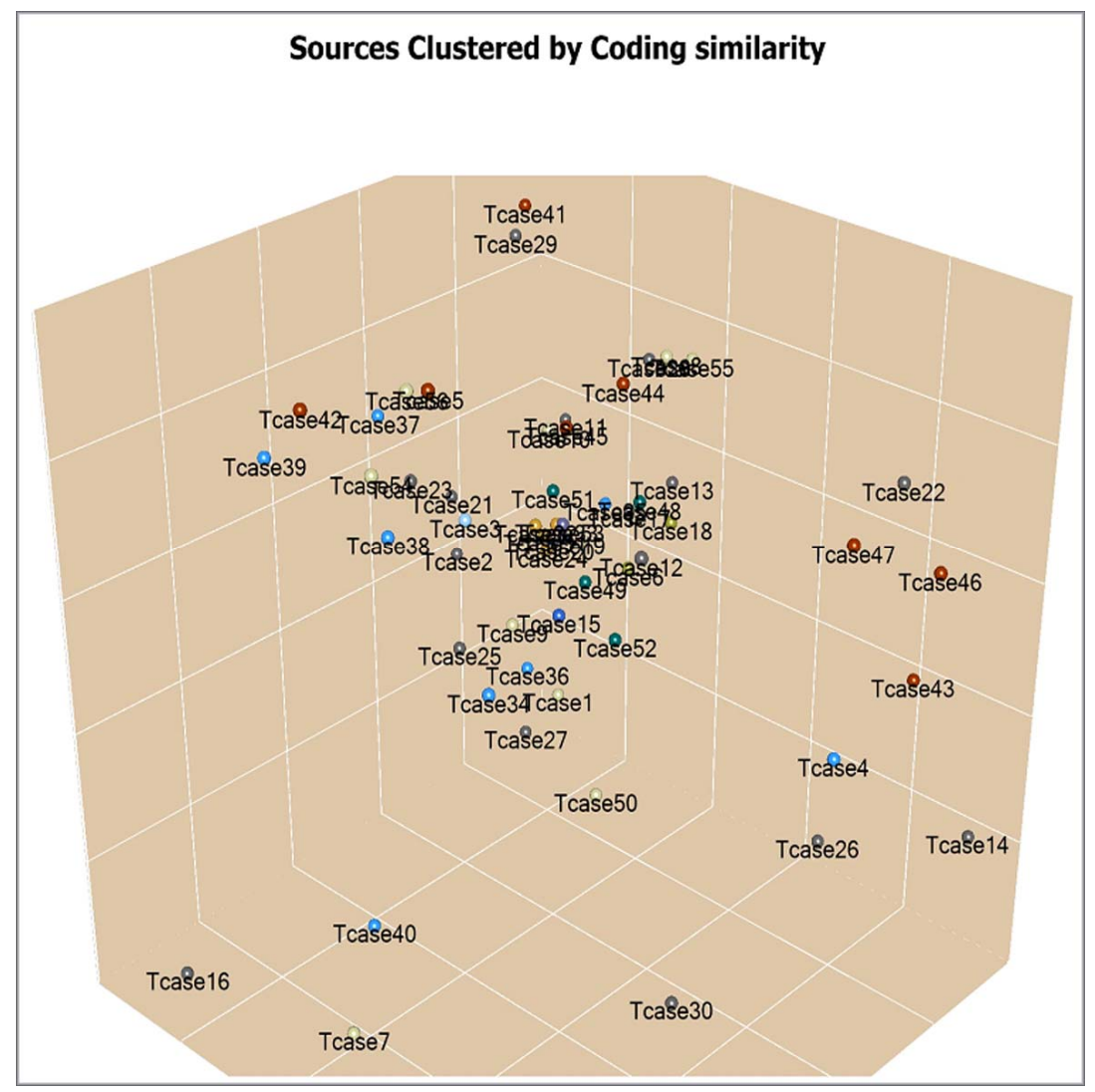

Figure 1.

Coding similarity of teachers' views on educational leaders (three dimensional). 
had a democratic mentality, is open to criticize, accepts his/her mistakes (as a person and administrator). However, he is not consistent in addressing people, and his behaviours" (T26). In relation to second theme one respondent stated that "Deficit in communication skills that lead to a lack of transparency on the reasons" (T55). The third weakness has been exemplified by two representative quotations. The first respondent points out to "Their lack of foresight for the future in personal and organizational level" (T6). And the second example stresses on vision and mission terms clearly saying that "He is not idealist as a principal. He does not assign targets. He does not also manage the mission and vision of the school" (T31). The following quotations exemplify rude side of a human being. One respondent stated that his school leader "Never hesitates to criticize and humiliate teachers in front of the students" (T38). In relation to theme five one respondent said "He warns successful staff as well as unsuccessful ones. Therefore, successful and unsuccessful staffs are not distinguished" (T3). Weakness referring the term "technology" was stated by a respondent as "They are unable to follow technological innovations" (T9). Another respondent stressed on "Insufficient technological know-

Table 1.

Principals' weak leadership characteristics according to teachers' views.

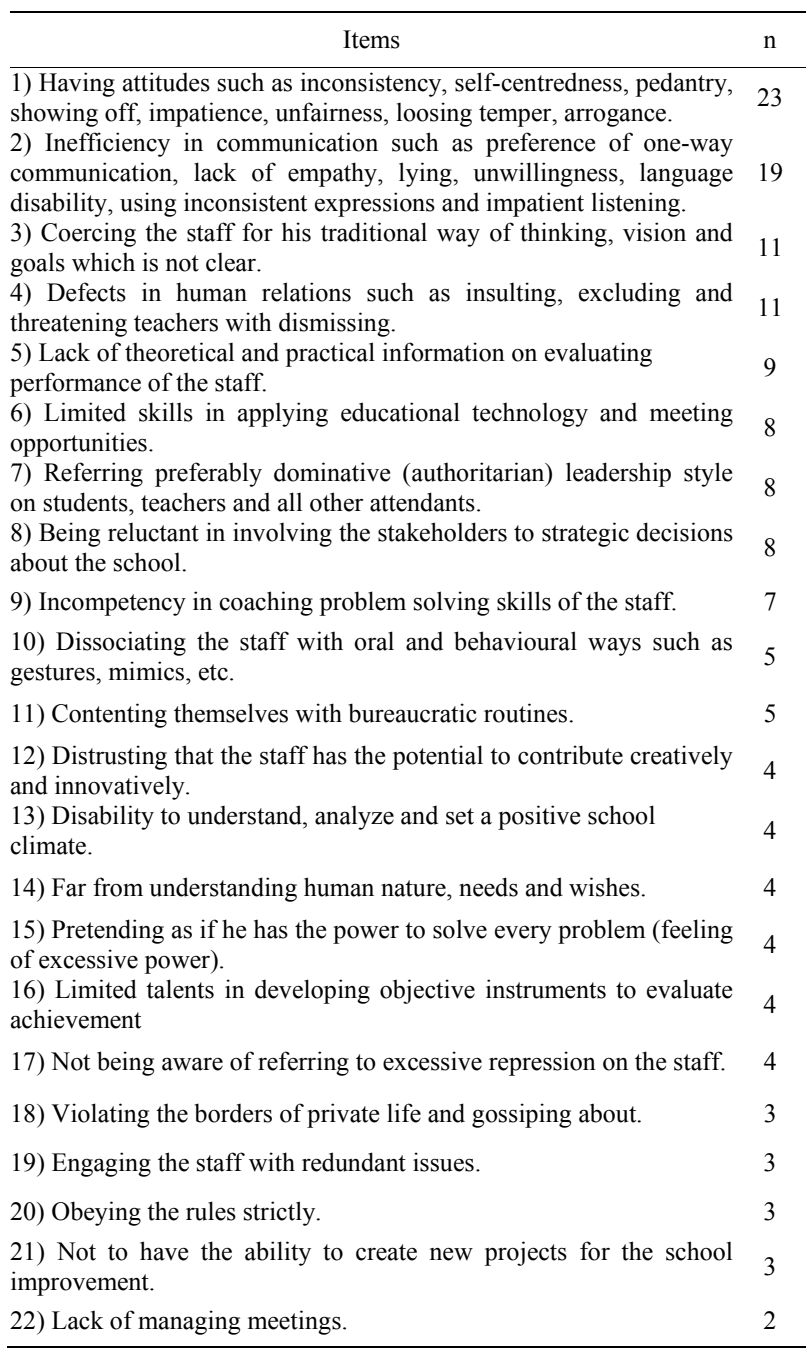

ledge" (T55). The quotation about authoritative tendency is also noteworthy. The respondent said that "I don't think he has leadership characteristics. He is only an administrator came with the examination. He does not understand human relations. He is rude and inconsistent in his speeches and he does not know where and what to say" (T39). In relation to eighth theme one respondent stated that "He doesn't like consulting to others much" (T29). Another one said "He ignores others' opinions, actually is not willing to listen to us" (T44).

Table 2 shows principals' strong leadership characteristics depending on the analysis of teachers' views. Two quotations have been presented to exemplify the first theme. The first respondent stated that one of his school leaders' strong characteristics is to be "good-minded and fair" (T11). In relation to theme two one respondent said about his school leader that "He is hardworking, sharing, gentle, and democratic" (T20). Another respondent also stated that "Our principal is very good, sometimes a little moody." (T54). The third theme stresses on the bases of human relations. One respondent said that "Our school principal gives moral support to people to provide team work when necessary" (T26). The fourth theme was inferred from such ideas as "Our principal encourages teachers in every field. He supports teachers in every task" (T6). In relation to schoolenvironment relations one respondent said "our school leader communicates with other stakeholders to increase the success in school. Establishes good dialogue with parents" (T42). In relation to theme six one respondent said that one of his school

Table 2.

Principals' strong leadership characteristics according to teachers' views.

\begin{tabular}{|c|c|}
\hline Items & $\mathrm{n}$ \\
\hline $\begin{array}{l}\text { 1) Have honest, fair, open minded, democratic, valuable, equal, } \\
\text { considerate and objective treatment to the staff. }\end{array}$ & 12 \\
\hline 2) Hardworking, gentle, friendly, polite, emotional. & 9 \\
\hline $\begin{array}{l}\text { 3) Positive human relations, creative motivation strategies and moral } \\
\text { support. }\end{array}$ & 9 \\
\hline 4) Support and encourage self development needs of the staff. & 8 \\
\hline $\begin{array}{l}\text { 5) Specialist on school-environment relations including parental, } \\
\text { governmental and non governmental institutions. }\end{array}$ & 8 \\
\hline 6) Reflect both self-confidence and trust to the employee. & 8 \\
\hline 7) Reflect personal communication style. & 8 \\
\hline $\begin{array}{l}\text { 8) Manage school budget successfully and talented in creating } \\
\text { financial supports. }\end{array}$ & 6 \\
\hline 9) Encourage and facilitate team and group works. & 6 \\
\hline 10) Skilful in integrating the staff by creating group activities. & 5 \\
\hline $\begin{array}{l}\text { 11) Skilful in chasing new opportunities in technological } \\
\text { developments. }\end{array}$ & 5 \\
\hline 12) Competent in management profession and pedagogy. & 5 \\
\hline 13) Practical and time saving in applying the final decision. & 5 \\
\hline 14) Inspiring in problem solving and crisis management. & 4 \\
\hline $\begin{array}{l}\text { 15) Reflecting a role model in creating a school culture based on } \\
\text { learning. }\end{array}$ & 4 \\
\hline 16) Adapt participative decision making. & 4 \\
\hline 17) Creative on adjusting physical facilities with learning needs. & 4 \\
\hline 18) Reflect good command of regulations. & 4 \\
\hline 19) Achievement oriented and student centred. & 3 \\
\hline 20) Reflect creative and inspiring managerial initiatives & 2 \\
\hline
\end{tabular}


leader's strong characteristics is "to have a self confident way of estimating the events and a trust in awareness of his followers including attendants, teachers and students" (T8). The quotations representing theme seven stresses "to have a self-way of expressing his ideas and wishes". One respondent said that "one of my school leader's strong characteristics lies always using the word "our" (T10). Another participant said that "what is strong among his characteristics is that the way he uses appropriate speaking styles which suits the person and the case" (T26). Some participants stated that one of their school leaders' major characteristics is the creative ability about financial issues. About these themes, a participant said that "My principal is successful in finding necessary sponsors for schools' demands" (T2).

Table 3 shows the findings about estimated characteristics of school leaders' in the fourth coming near future based on teachers' experiences and views. The first theme, given in Table 3, has the highest frequency which shows that the main focus is on the issues about information and communication technologies. In relation to these theme one participant said "To have a good command on ICT resources and know how to use them in order to use a school more effectively and according to the advances in technology" (T52). In relation to the second theme a respondent said that a school leader must have the ability "To follow up change and analyze changing aspects of organization continuously" (T1). Another respondent contributed the theme adding that "A school principal must be educational leader. He should pursue innovations, developments closely. He should also create atmosphere where those innovations will be run. $\mathrm{He}$ should be pioneer" (T28). The third theme which is about motivational issues was derived out of the statements such as "A school leader will be expected to know how to appreciate teachers by putting his ego aside" (T22). The fourth theme given in Table 3, seems to have a focus on cooperation and communication in describing the characteristics of a school leader in the future. One participant stated that "He must provide an opportunity for open dialogue/access to parents to foster cooperation at home and in the community. He should be a model for his staff and a motivator" (T46). In relation to theme five a respondent said that "Our principal has a personality which necessitates renewal and adaptation to developments regularly. According to me, he must be one step ahead in front of us, because, he is the person who is expected to represent willingness, intelligence and academic proficiency" (T19). Several respondents contributed theme six as in the following quoted terms: "Being a benevolent man" (Tcase $12>$ Reference 3), "Being gentle" (T12), "they must first be leaders of good, strong and honourable character" (T17), "they must be intelligent" (T17), "Should not show inconsistent and contradictious behaviours and attitudes" (T22), "reliability and openness" (T21), "intelligence and academic proficiency" (T19), "Having dynamism to follow up changes and developments" (T36). In relation to theme seven a respondent said that "A school leader should create positive school atmosphere" (T28). Another one added that "Principals should provide teachers with comfortable work conditions and work effectively" (T35). Some respondents seem to focus on vision and mission abilities of a school leader's characteristics in the future. In relation to the theme, one respondent said that "He should have an overall vision for his school" (T46). Another one stated that "In general principals should be clear about their goals, be fair to all teachers and not behave in favour of some, be transparent in their decision making process,
Table 3.

Principals' estimated leadership characteristics according to teachers' views.

\begin{tabular}{|c|c|}
\hline Items & $\mathrm{n}$ \\
\hline $\begin{array}{l}\text { 1) Should be able to supply the school with technological resources, } \\
\text { and encourage teachers to use technology effectively. }\end{array}$ & 20 \\
\hline $\begin{array}{l}\text { 2) Must be able to analyze change process, pursue innovations and } \\
\text { adapt to change demands. }\end{array}$ & 15 \\
\hline $\begin{array}{l}\text { 3) Must have effective motivational strategies for all parties of a } \\
\text { school. }\end{array}$ & 15 \\
\hline $\begin{array}{l}\text { 3) Should foster an effective cooperation by setting effective } \\
\text { communication among teachers, students, parents and other parts } \\
\text { of the community. }\end{array}$ & 14 \\
\hline $\begin{array}{l}\text { 4) Should have enough knowledge and experience in school and } \\
\text { public management and self development strategies. }\end{array}$ & 13 \\
\hline $\begin{array}{l}\text { 5) Will have objective, honourable, benevolent, gentle, reliable, open } \\
\text { minded, consistent and dynamic character. }\end{array}$ & 10 \\
\hline $\begin{array}{l}\text { 6) Must have the ability to create a competitive, innovative and } \\
\text { positive school culture and climate. }\end{array}$ & 7 \\
\hline $\begin{array}{l}\text { 7) Should have an overall clear school vision, mission and ability to } \\
\text { communicate them effectively. }\end{array}$ & 7 \\
\hline 8) Will have close human relations with the staff. & 6 \\
\hline $\begin{array}{l}\text { 9) Will be transparent in making strategic decisions with the } \\
\text { employees for effective innovation and change continuously. } \\
\text { 10) Should have a good command on the mother tongue and a } \\
\text { second language and inspire teachers to learn and use a second } \\
\text { language. }\end{array}$ & 6 \\
\hline 11) Will encourage and facilitate teachers' development. & 6 \\
\hline $\begin{array}{l}\text { 12) Will be professional in both areas pedagogy and management } \\
\text { profession. }\end{array}$ & 6 \\
\hline $\begin{array}{l}\text { 13) Creates and insists on building a team spirit including each } \\
\text { individual in the whole organization. }\end{array}$ & 5 \\
\hline 14) Should be an alternative developer and problem solver. & 5 \\
\hline $\begin{array}{l}\text { 15) Will be able to measure and evaluate the staff performance with } \\
\text { objective criteria. }\end{array}$ & 5 \\
\hline 16) Must be sensitive and respectful to diversities. & 5 \\
\hline 17) Will be student centred and achieven & 4 \\
\hline 18) Will reflect democratic attitudes and behaviours. & 4 \\
\hline $\begin{array}{l}\text { 19) Good follower of contemporary educational agenda and the } \\
\text { related developments. }\end{array}$ & 3 \\
\hline 20) Will adapt coaching role. & 3 \\
\hline 21) Will be more talented on financial issues of the school. & 3 \\
\hline 22) Will reflect less tendency and dependency on bureaucracy. & 2 \\
\hline 23) Should refl & 2 \\
\hline
\end{tabular}

value opinions, have an open ear for all teachers" (T54).

Table 4 shows some additional critical issues found in the process of content analysis which is likely to open a new discussion on the debate. In the first theme given in Table 4, the respondents concentrate on the relationship of nature of the system and effective leadership. The idea stems from the premise that centralized systems limit leadership initiative. The second theme shows that competency of the school leaders and appointment procedures accordingly should be revised according to the needs of the new age which is shaped by unlimited information processing. The third theme stresses on finding ways for providing dynamism in the management positions. The last critical issue found in the analysis is the unfavourable results appear because of inconsistent decisions and changes made by policy makers and educational authorities. The respondents refer to the premise that if the educational systems are successfully transformed to have consistent, constant and flexible characters in relation to local, national and global needs 
Table 4.

Some additional critical issues in the future of leadership.

\section{Items}

1) Decentralization strengths the leader.

2) Principals competencies must be redefined and principals should be appointed accordingly

3) School principals should often be rotated or alternative ways should be considered in appointment.

4) Often changes made in state policy makes a barrier in front of effective leadership

then, the future leaders are likely to be more effective.

\section{Discussions and Conclusions}

The results demonstrated that the most common leadership characteristics was expected and estimated on the issue of processing information using computer based technology. More respondents stated that current leaders had limited skills in using the latest technologies adapted to educational needs than these who thought that current principals were skilful in chasing new technology for innovative opportunities. On the other hand, almost half of the respondents estimated technology to be of first priority of a leader's characteristics. The respondents' second expectation which reflects transformational character is consistent with the first, in that the underlined terms such as meeting change demand, the need to pursue innovation and keeping conscious to improve are likely to be the major characteristics required to help a leader to keep alert for revising his competency in rapidly developing technological issues. Among one of the most mentioned leadership characteristics for future by the participants were about motivational strategies. This finding is significant in that although technology was blessed first for future leadership, later we understand that the human side of the educational organizations has been still seen as the core of the issue. Soon after the motivational strategies communicative skills were reported by the respondents to be an expected leadership characteristics in the future. This finding also leads us to think that human resources were thought to remain as the most important part of the educational organizations whereas, technology as the mean not the end. Among the later characteristics for future leadership the focus was on integrating personal characteristics, such as experience, reliability, and consistency; professional characteristics such as, having a clear vision, decision making and organizational characteristics, such as providing a positive school culture, evaluating performance etc.

An overview of the themes common to three facets of the study, given in Table 1-3, show that technology, public management skills, personal characteristics, vision, human relations, transparency in decision making, communicability internationally, competency in teaching profession, team management capacity, problem solving skills, performance evaluation and achievement orientation, respectability to diversities, attitudes in relation to democratic and value based management, financial issues, flexibility in applying bureaucracy, a leader's identity and its effects on the organizational processes, the ability to communicate, whether exerting authoritative or democratic style, trust or vice versa to the staff contribution, respecting human rights, ability to conduct meeting, motivation strategies, self-developmental issues, providing school-environment relations, talents in creating belongingness, skills to effect school culture and climate, providing maximum benefit from physical environment and undertaking managerial initiatives are likely to be inferred as the major domains in dealing with leadership issue. It can be asserted that all of these subjects are one of the most significant finding of this study because they are in nature seem to represent the criteria that teachers used in their evaluation.

What we can also learn from the findings is that the respondents of this research have in their minds the idea that educating people undoubtedly will be based on "human relations", "face to face" and "in the classrooms teaching" while technology and its all kinds of derivatives are presumed only to be the means to reach the goals. So, we can infer that although information and communication technologies have caused to some degree confusion in the minds about the role of teachers in educating students and the role of the school leaders in this paradigmatic shift, it seems that teachers and school leaders do not reflect any kind of tendency to substitute the means with the ends. On the other hand, the findings given in Table 4, calls for decentralization of the education system and deciding on how schools will be managed accordingly; how school leaders will be trained and in what ways they will be appointed arise a comprehensive debate which includes policy makers and educational authorities in.

Consequently, the purpose of this study was to get teachers' perceptions about current state of their school leaders' characteristics, identifying and classifying them in weak and strong facets and trying to get a picture of future leadership characteristics depending on their estimations. The results illustrated that weak, strong and estimated characteristics as they were stated by the respondents were consistent in that they provided three kinds of data. The first kind provided us the characteristics that teachers related to leadership and how they evaluate their leaders accordingly. The second kind of the data provided us what characteristics teachers estimate to a school leader in the future. The third and perhaps the most significant data were to get a picture of the criteria which were used by teachers in evaluating their current state of school leaders derived out of the coherency in stating the weak, strong and estimated characteristics. Further qualitative analysis can be carried on by comparing current state of leadership in centralized and decentralized education systems and how teachers picture the future of school leadership. Furthermore, further qualitative analysis regarding demographic variables can also help to understand the issue better.

\section{Acknowledgements}

This study was supported by the University of Akdeniz, the Department of Scientific Research Projects Management.

\section{REFERENCES}

Barendsen, L., \& Gardner, H. (2006). The three elements of good leadership in rapidly changing times. In F. Hesselbein, \& M. Goldsmith (Eds.), The leader of the future 2 visions, strategies, and practices for the new era (pp. 265-280). San Francisco: Jossey-Bass A Wiley.

Coates, M. (2010). Future tense. In M. Coates (Ed.), Future schools in shaping a new educational landscape: Exploring possibilities for education in the 21st century (pp. 3-8). London: GBR: Continuum International Publishing.

Collay, M. (2006). Discerning professional identity and becoming bold, socially responsible teacher-leaders. Educational Leadership and Ad- 
ministration: Teaching and Program Development, 18, 131-146.

Day, C., Harris, A., \& Hadfield M. (2001). Grounding knowledge of schools in stakeholder realities: A multi-perspective study of effective school leaders. School Leadership \& Management, 21, 19-42. doi:10.1080/13632430120033027

Fink, D. (2005). Developing leaders for their future not our past. In M. J. Coles, \& G. Southworth (Eds.), Developing leadership: Creating the school of tomorrow (pp. 1-20). England: Open University Press McGraw Hill House.

Fink, D., \& Brayman, C. (2006). School leadership succession and the challenges of change. Educational Administration Quarterly, 42, 6289. doi:10.1177/0013161X05278186

Fullan, M. (1998). Leadership for the 21 st century: Breaking the bonds of dependency. Educational Leadership, 55, 1-6.

Goldring, E. (2002). Understanding the evolving concept of leadership in education roles, expectations, and dilemmas. Educational leadership reports and recommendations from a national invitational conference. The LSS Review, 1, 1-31.

Grogan, M., \& Andrews, R. (2002). Defining preparation and professional development for the future. Educational Administration Quarterly, 38, 33-256.

Haris, A. (2010). Future leadership: Challenges and implications. In M. Coates (Ed.), Future schools: Shaping a new educational landscape: Exploring possibilities for education in the 21st century (pp. 70-71). London: GBR: Continuum International Publishing.

Kus, E. (2007). Qualitative Research Techniques. Baski, Ankara: Ani Yayincilik.

Leithwood, K., Steinbach, R., \& Jantzi, D. (2002). School leadership and teachers' motivation to implement accountability policies. Educational Administration Quarterly, 38, 94-119.

Leithwood, K., Harris, A., \& Hopkins, D. (2008). Seven strong claims about successful school leadership. School Leadership and Manage- ment, 28, 27-42. doi:10.1080/13632430701800060

Mariasse, A. L. (1985). Vision and leadership: Paying attention to intention. Peabody Journal of Education, 63, 150-173. doi:10.1080/01619568509538505

Mason, J. (2002). Qualitative researching (2nd ed.). London: Sage Publications.

Murphy, J., \& Walberg, H. J. (2002). Educational leadership reports and recommendations from a national invitational conference. The LSS Review, 1, 1-30.

OECD, (2009). Improving school leadership: The toolkit. www.oecd.org/edu/schoolleadership

Patton, M. Q. (1990). Qualitative evaluation and research (2nd ed.). London: Sage Publications.

Reilly, E. C. (2007). Leadership in a global society: Habits of mind, of heart, and of action. Educational Leadership and Administration: Teaching and Program Development, 19, 139-147.

Rubin, H., \& Rubin, I. (1995). Qualitative interviewing: The art of hearing data. Thousand Oaks, CA: Sage Publications.

Sandmann, L. R., \& Vandenberg, L. (1995). A framework for 21st century leadership. Journal of Extention, 33, 198. http://www.joe.org/joe/1995december/a1.html

Slater, L. (2008). Pathways to building leadership capacity. Educational Management Administration \& Leadership, 36, 55-69. doi: $10.1177 / 1741143207084060$

Witziers, B., Bosker, R. J., \& Krüger, M. L. (2003). Educational leadership and student achievement: The elusive search for an association. Educational Administration Quarterly, 39, 398-425. doi: $10.1177 / 0013161 \mathrm{X} 03253411$

Yildirim, A., \& Simsek, H. (2006). Research Methods in Social Sciences. Ankara: Seckin Yayincilik. 